\title{
NOZZLE COOLING OF HOT SURFACES WITH VARIOUS ORIENTATIONS
}

\author{
Jana ONDROUSKOVA, Tomas LUKS, Jaroslav HORSKY`
}

\begin{abstract}
The aim of this research is an investigation of hot surface orientation influence on heat transfer during cooling by a nozzle. Two types of nozzles were used for the experiments (air-mist nozzle and hydraulic nozzle). A test plate was cooled in three positions - top, side and bottom position. The aim was to simulate a cooling situation in the secondary zone of a continuous casting machine. Temperature was measured in seven locations under the cooled surface by thermocouples. These data were used for an inverse heat conduction problem and then boundary conditions were computed. These boundary conditions are represented by surface temperature, heat transfer coefficient and heat flux. Results from an inverse calculation were compared in each position of thermocouples separately. The total cooling intensity was specified for all configurations of nozzles and test plate orientation. Results are summarised in a graphical and numerical format.
\end{abstract}

\section{INTRODUCTION}

The cooling intensity of nozzles was measured at a laboratory stand [1],[2]. The results obtained such as heat transfer coefficient and its dependency on the surface temperature enables summarising of the cooling effect of the nozzles. This measuring was conducted only under the laboratory conditions such measuring is sometimes simpler than the measuring in a plant. This paper shows the differences in surface orientation within the experiments conducted.

Different position of the surface means different orientation of gravity field. At the top position gravity affects to water velocity. It means an assumption of a higher impact pressure on the testing surface. At the bottom position the effect is the opposite. Lower and higher impact pressure means a lower and higher steam layer on the surface and a change of the cooling intensity.

For the testing plate vertically oriented the gravity field influences the direction of water stream and increases the cooling intensity on the bottom roll.

All these effects strongly depend on the following parameters: water pressure, distance of nozzles and type of the nozzles; these parameters are the objects of the measuring presented here.

\footnotetext{
- Jana Ondrouskova, ondrouskova@lptap.fme.vutbr.cz, Tomas Luks, luks@lptap.fme.vutbr.cz, Jaroslav Horsky, horsky@fme.vutbr.cz, Brno University of Technology, Faculty of Mechanical Engineering, Heat Transfer and Fluid Flow Laboratory, Technicka 2, 61669 Brno, Czech Republic
}

This is an Open Access article distributed under the terms of the Creative Commons Attribution License 2.0, which permits unrestricted use, distribution, and reproduction in any medium, provided the original work is properly cited. 


\section{EXPERIMENT}

The investigation of hot surface orientation influence on heat transfer was done from the data obtained from the experiments conducted at the laboratory, see Table 1.

Table 1 Table of experiments

\begin{tabular}{|c|c|c|c|c|c|c|c|}
\hline Position & Experiment & Nozzle & $\begin{array}{l}\text { Roll } \\
\text { gap } \\
{[\mathrm{mm}]}\end{array}$ & $\begin{array}{l}\text { Distance } \\
{[\mathrm{mm}]}\end{array}$ & $\begin{array}{l}\text { Flow rate } \\
{[1 / \mathrm{s}]}\end{array}$ & $\begin{array}{l}\text { Water } \\
\text { pressure } \\
\text { [bar] }\end{array}$ & $\begin{array}{l}\text { Air } \\
\text { pressure } \\
\text { [bar] }\end{array}$ \\
\hline \multirow{6}{*}{ Top } & $\mathrm{T} 1$ & Air-mist & 39 & 190 & 0.284 & 3.19 & 2 \\
\hline & $\mathrm{T} 2$ & Air-mist & 39 & 190 & 0.379 & 4.39 & 2 \\
\hline & T3 & Hydraulic & 30 & 207 & 0.032 & 0.72 & \\
\hline & T4 & Hydraulic & 30 & 207 & 0.120 & 10.1 & \\
\hline & T5 & Hydraulic & 30 & 500 & 0.032 & 0.7 & \\
\hline & T6 & Hydraulic & 30 & 500 & 0.120 & 10.62 & \\
\hline \multirow{6}{*}{ Side } & S1 & Air-mist & 39 & 190 & 0.284 & 3.16 & 2 \\
\hline & S2 & Air-mist & 39 & 190 & 0.379 & 4.38 & 2 \\
\hline & S3 & Hydraulic & 30 & 207 & 0.032 & 0.69 & \\
\hline & S4 & Hydraulic & 30 & 207 & 0.120 & 10.2 & \\
\hline & S5 & Hydraulic & 30 & 500 & 0.032 & 0.68 & \\
\hline & S6 & Hydraulic & 30 & 500 & 0.120 & 10.6 & \\
\hline \multirow{6}{*}{ Bottom } & B1 & Air-mist & 39 & 190 & 0.284 & 3.15 & 2 \\
\hline & B2 & Air-mist & 39 & 190 & 0.379 & 4.36 & 2 \\
\hline & B3 & Hydraulic & 30 & 207 & 0.032 & 0.67 & \\
\hline & B4 & Hydraulic & 30 & 207 & 0.120 & 9.98 & \\
\hline & B5 & Hydraulic & 30 & 500 & 0.032 & 0.64 & \\
\hline & B6 & Hydraulic & 30 & 500 & 0.120 & 9.8 & \\
\hline
\end{tabular}

The measurements were conducted with a nozzle situated above a plate. There are two sheets on the plate simulating the rolls. The nozzle was sprayed between these two halfrolls. Table 1 shows the experiments measured in three positions - top, side and bottom. These are the positions of the nozzle towards the plate.

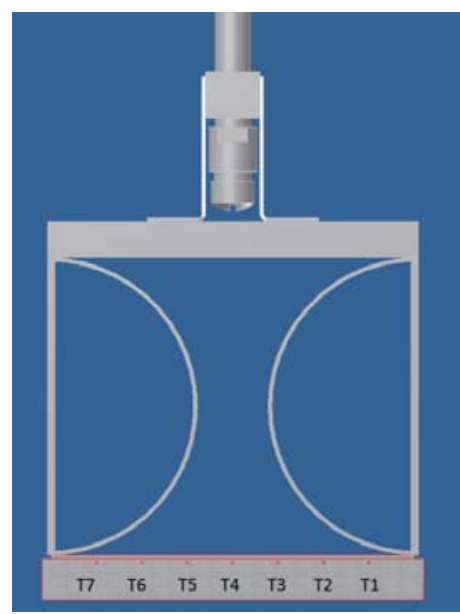

Figure 1: Test plate with a roll diameter of $165 \mathrm{~mm}$ and a nozzle distance of $190 \mathrm{~mm}$ 
The experiments were measured with two types of nozzles and two different diameters of the rolls. The first nozzle is an air-mist nozzle with a spraying angle of $90^{\circ}$, which was used with a $210 \mathrm{~mm}$ long plate. The gap between the rolls is $39 \mathrm{~mm}$ and the roll diameter is $165 \mathrm{~mm}$, see Figure 1 . The nozzle was $190 \mathrm{~mm}$ above the surface of the plate and flow rates were $0.284 \mathrm{l} / \mathrm{s}$ and $0.379 \mathrm{l} / \mathrm{s}$.

The second nozzle is a hydraulic nozzle. It was used with a test plate $350 \mathrm{~mm}$ long. The gap between the rolls is $30 \mathrm{~mm}$ and the roll diameter is $219.9 \mathrm{~mm}$. This nozzle was used for two distances, 207 and $500 \mathrm{~mm}$, and two flow rates, $0.032 \mathrm{l} / \mathrm{s}$ and $0.12 \mathrm{l} / \mathrm{s}$. In Figure 1 there are seven holes for the thermocouples which were placed $4 \mathrm{~mm}$ under the surface.

The following Figure 2 shows the data recorded during the measurements at the top position of the nozzle, measured with an air-mist nozzle with a flow rate of water of $0.284 \mathrm{l} / \mathrm{s}$ and air pressure of 2 bar.

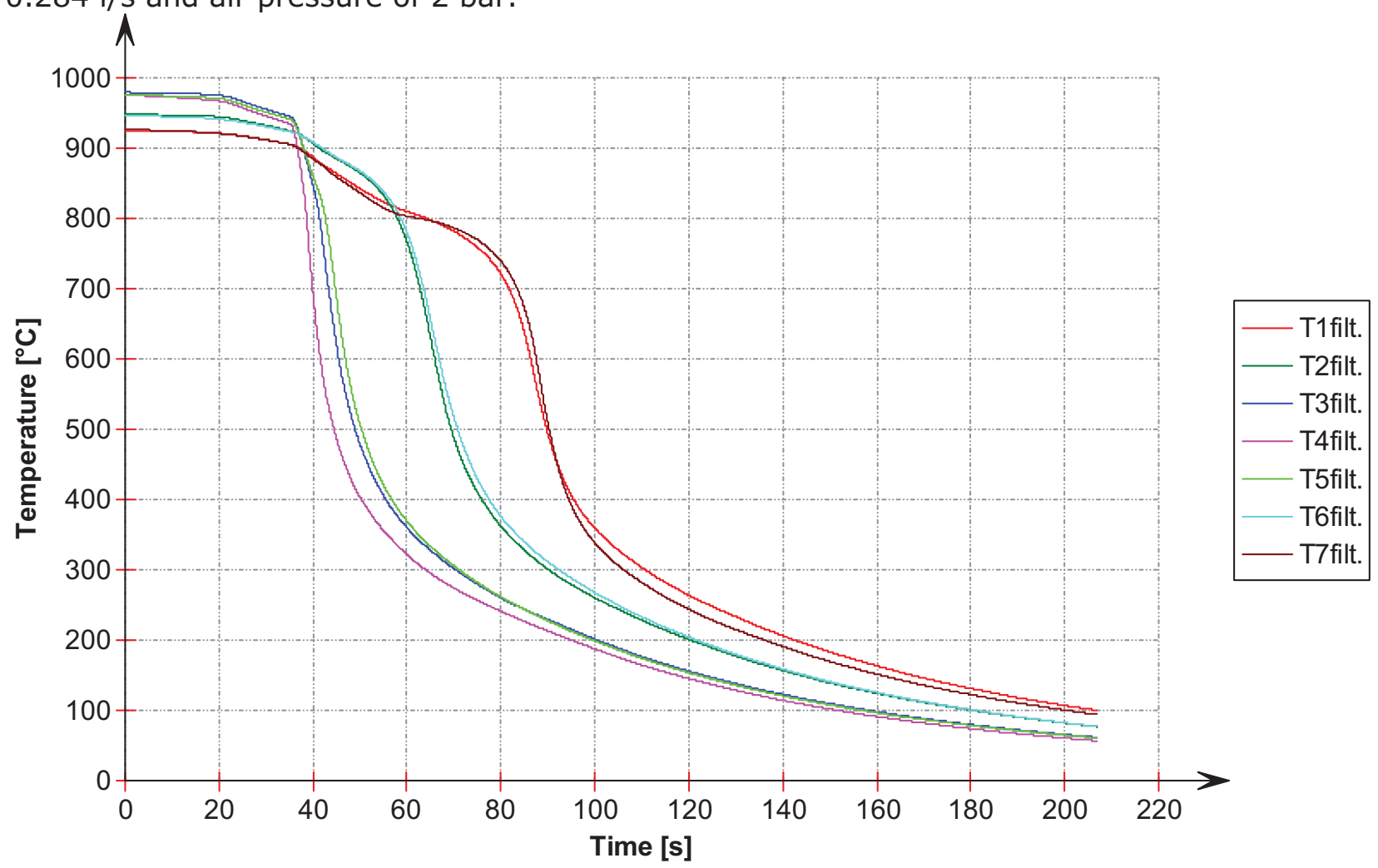

Figure 2: Experiment T1 - position top, air-mist nozzle, flow rate $0.284 \mathrm{l} / \mathrm{s}$.

\section{Calculating of boundary conditions}

From the measured temperatures time dependent boundary conditions were calculated by the inverse heat conduction problem. These boundary conditions are heat flux, heat transfer coefficient, and surface temperature. For computation, Beck's sequential approach is used [3]. This method uses a sequential estimation of the time varying boundary conditions and future time steps. First, the sum of squares error is computed using $f$ future time steps when the measured temperatures $T_{i}^{*}$ are compared with the computed temperatures $T_{i}$ at the current time $m$ :

$$
S S E=\sum_{i=m+1}^{m+f}\left(T_{i}^{*}-T_{i}\right)^{2}
$$


Temperatures $T_{i}$ are computed from a forward solver e.g. FDM, FEM, FVM. Using the linear minimization theory surface heat flux $q$ in time $m$ is calculated by minimizing equation (1)

$$
q^{m}=\frac{\sum_{i=m+1}^{m+f}\left(T_{i}^{*}-\left.T_{i}\right|_{q^{m}=0}\right)^{2} \zeta_{i}}{\sum_{i=m+1}^{m+f}\left(\zeta_{i}\right)^{2}}
$$

Where:

$\left.T_{i}\right|_{q^{m}=0}$ are the temperatures in the thermocouple, embedded in the sensor, and computed from the forward solver using all previously computed heat fluxes without $q^{m}$.

$\zeta_{i}$ is a sensitivity of the sensor with the thermocouple at time index $i$ to the heat flux pulse at time $m$. These sensitivity coefficients physically indicate an increase of temperature in the thermocouple per unit of heat flux on the surface. Sensitivity coefficient is defined as

$$
\zeta_{i}=\frac{\partial T_{i}}{\partial q^{m}},
$$

When surface temperatures $T_{0}^{m}$ and surface heat fluxes $q^{m}$ are known; then the heat transfer coefficient can be computed as follows:

$$
\operatorname{HTC}^{m}=\frac{q^{m}}{T_{\infty}^{m}-\left(T_{0}^{m}+T_{0}^{m-1}\right) / 2}
$$

$T_{\infty}^{m}$ is an ambient temperature.

\section{RESULTS FROM EXPERIMENTS}

From the experiments the data with temperature in the sensors were obtained. Then, these temperatures were used as input for the inverse heat conduction problem and surface temperatures, heat fluxes and heat transfer coefficients were computed. The following Figures 3 and 4 show an example of the computed surface temperatures and heat transfer coefficients (HTC) respectively.

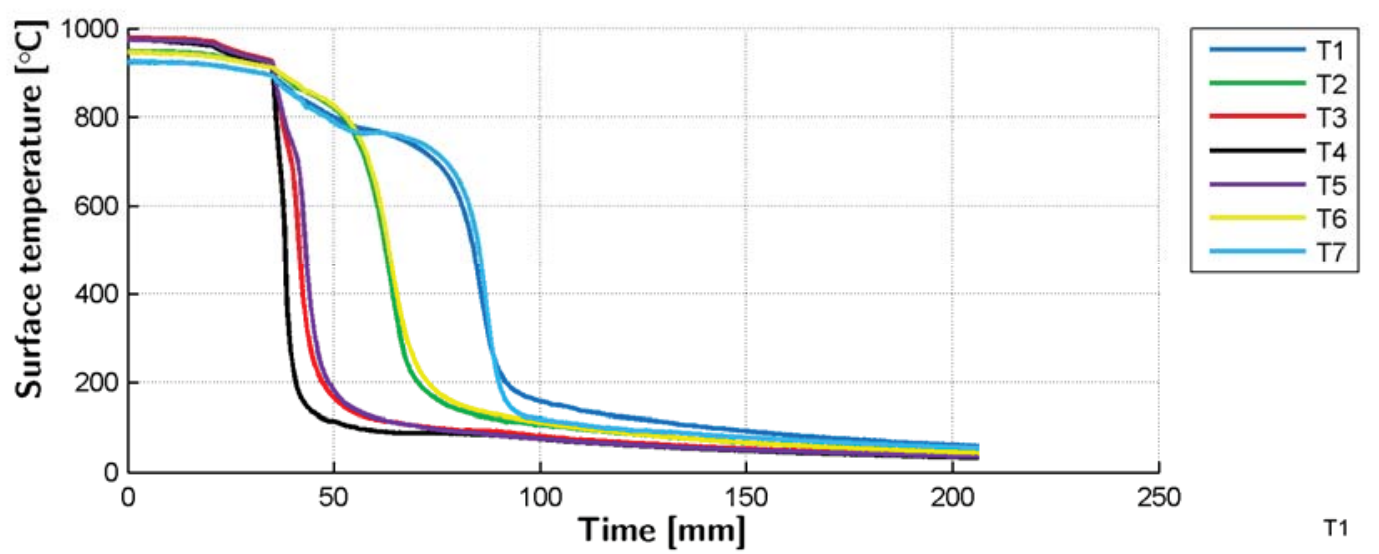

Figure 3: Experiment T1 - Surface temperature (position top, air-mist nozzle, flow rate $0.284 \mathrm{I} / \mathrm{s}$ ) 


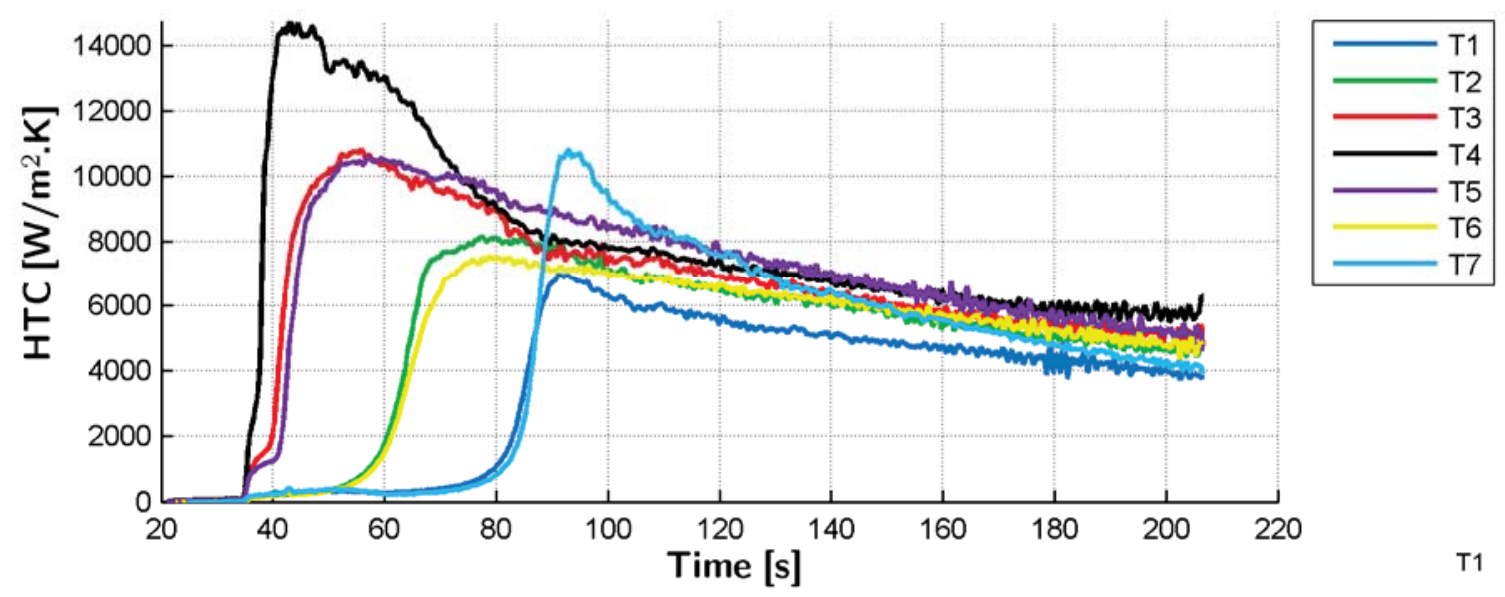

Figure 4: Experiment T1 - Heat transfer coefficient (position top, air-mist nozzle, flow rate $0.284 \mathrm{I} / \mathrm{s}$ ).

\section{COMPARISON}

Raw results from an inverse calculation were used in the first observation. 3D graph of surface temperature in time and position were created for each experiment. These results show the differences for different surface orientations. These graphs also show homogeneity of the cooling. In vertical orientation of testing we can see the differences between the top and bottom rolls.
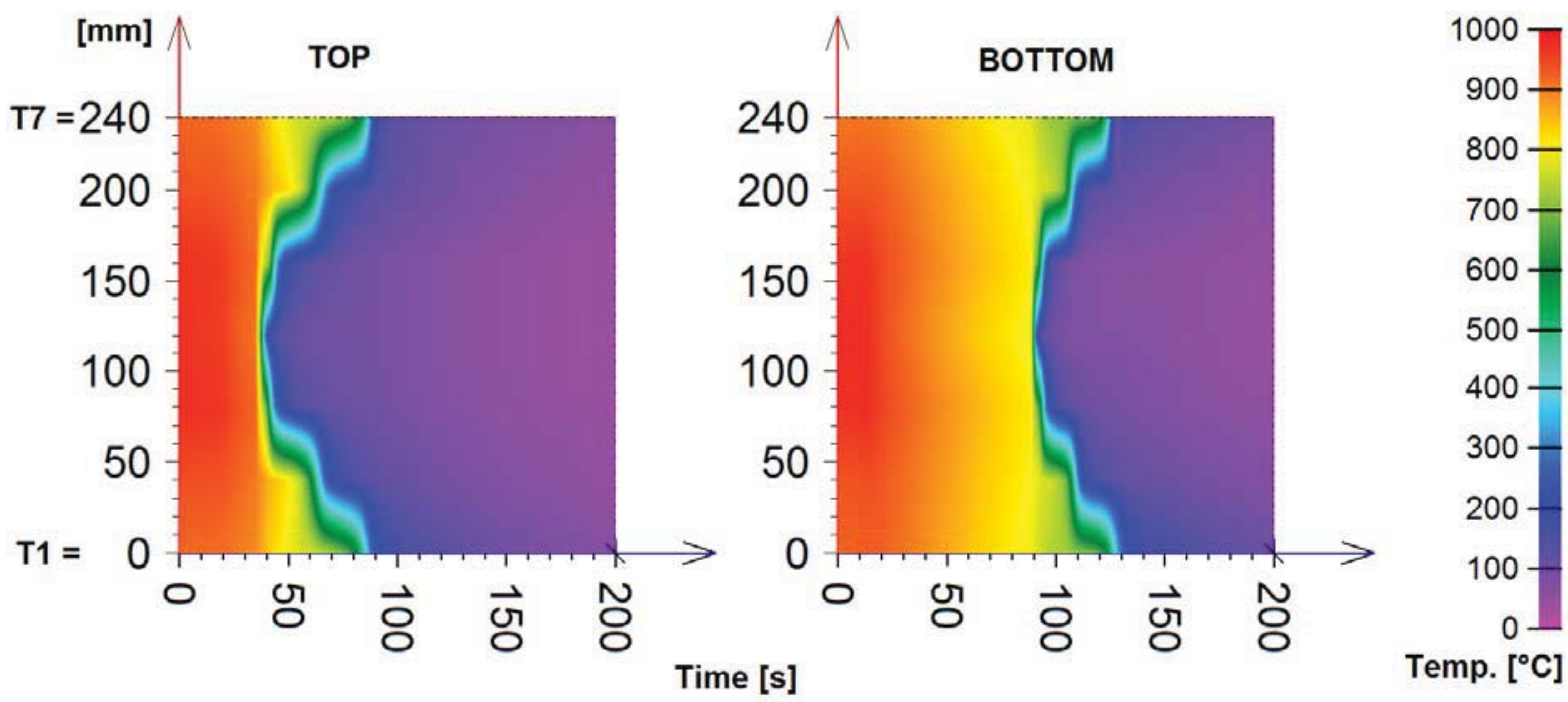

Figure 5: Experiment T1,B1 - Raw results from inverse calculation - surface temperature vs. time vs. position 


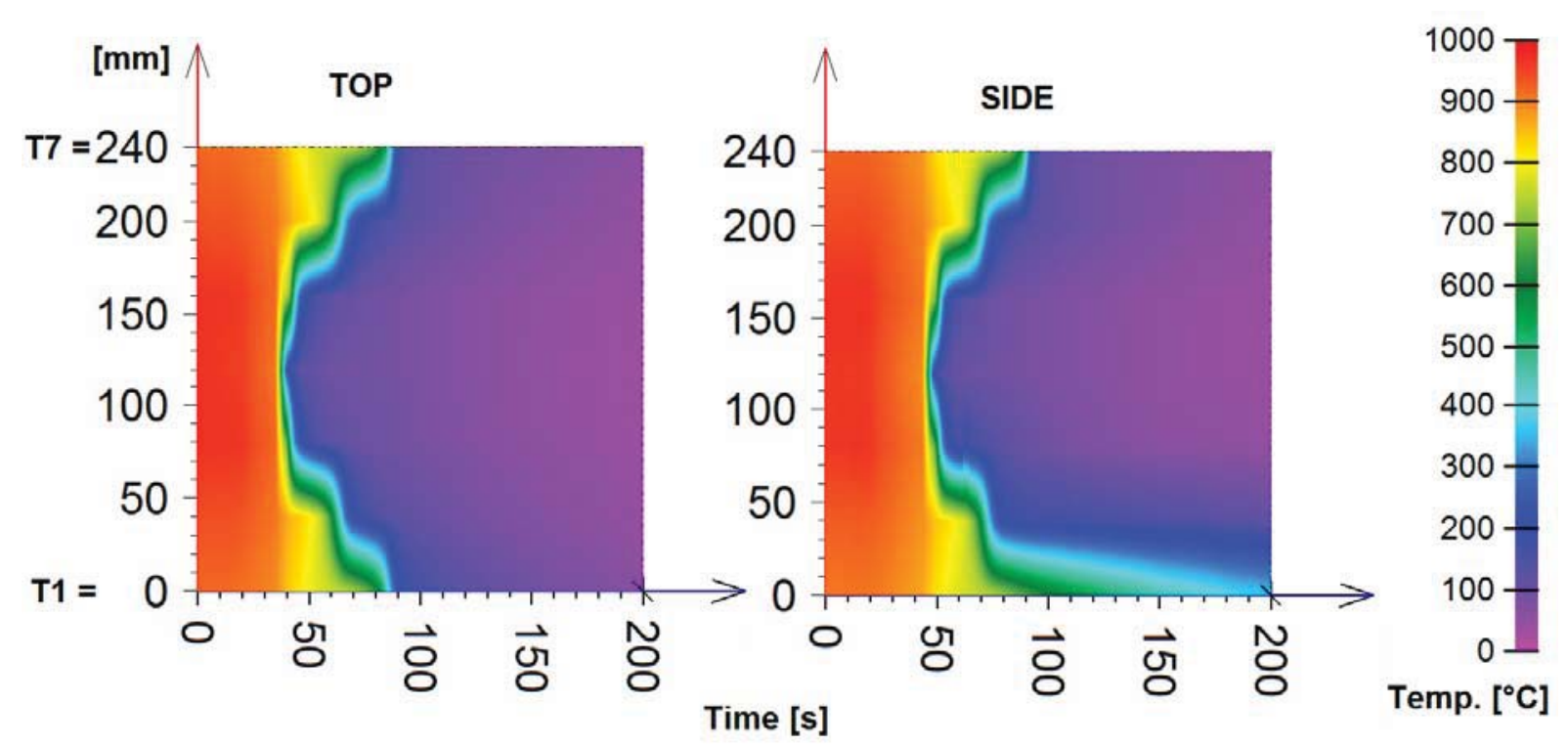

Figure 6: Experiment T1, S1 - Raw results from inverse calculation - surface temperature vs. time vs. position

As the starting temperatures are not the same in all experiments and also for a better comparison HTC vs. surface temperature was observed. The second type of graph used an average HTC in a specific temperature interval and showed cooling intensity along the test plate for different surface orientations. The graphs below presented the results for low pressure in each configuration. For a lower pressure we could expect higher influences caused by the surface orientation.

\section{Air-mist nozzle - 190mm distance}

An experiment with a 3.2 bar water pressure was conducted. Influences by surface orientation are very low. Only in boundary thermocouples there are quantifiable differences. A slightly shift of the temperature where a fully wetting ability of the surface, i.e. Leidenfrost effect, caused by the surface orientation is presented in Figure 8. In vertical orientation of the test plate, see thermocouple T1 in Figure 7, we can see a decreasing cooling intensity.

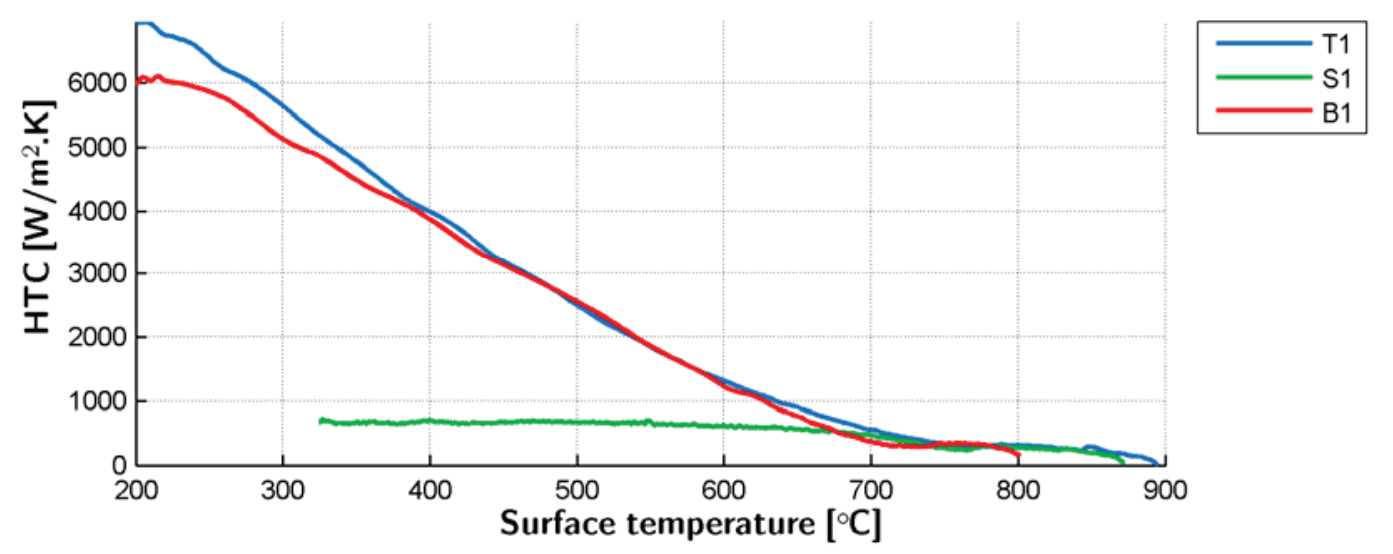

Figure 7: Thermocouples T1 - HTC vs. surface temperature for different orientation of testing plate 


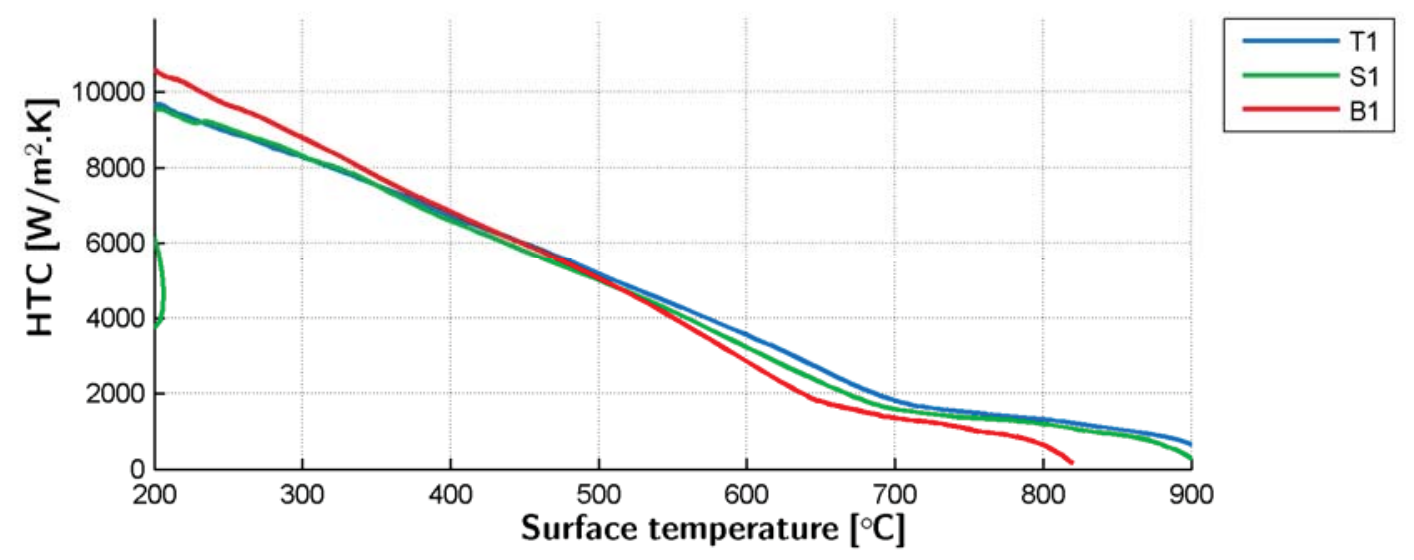

Figure 8: Thermocouples T3 - HTC vs. surface temperature for different orientation of testing plate

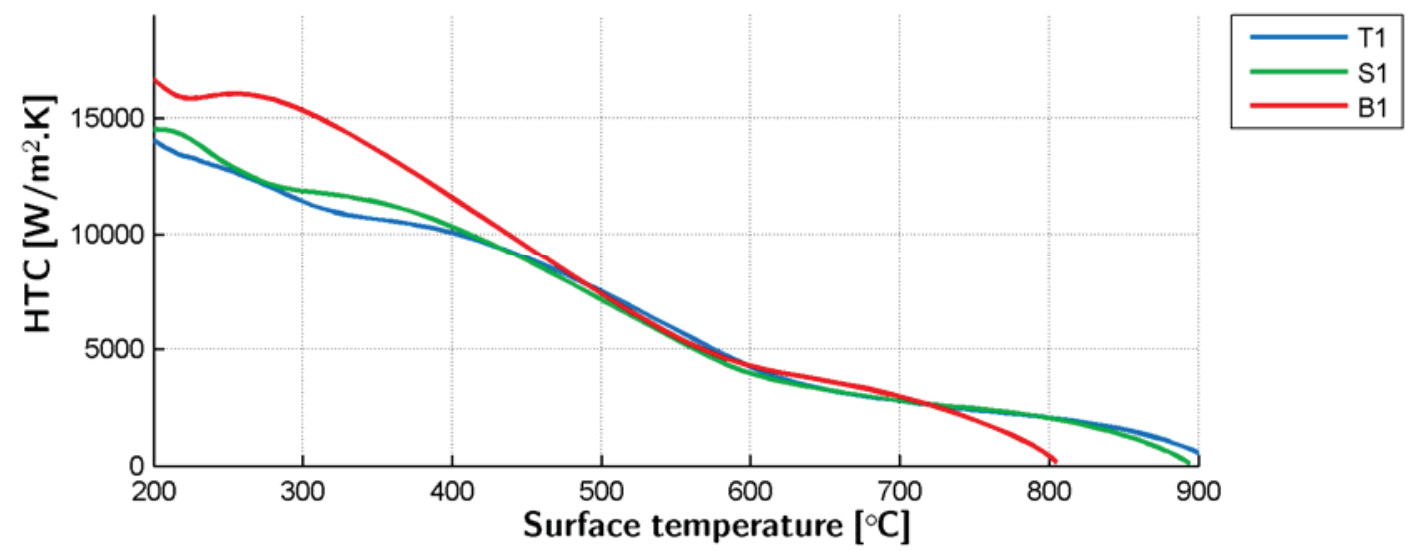

Figure 9: Thermocouples T4 - HTC vs. surface temperature for different orientation of testing plate

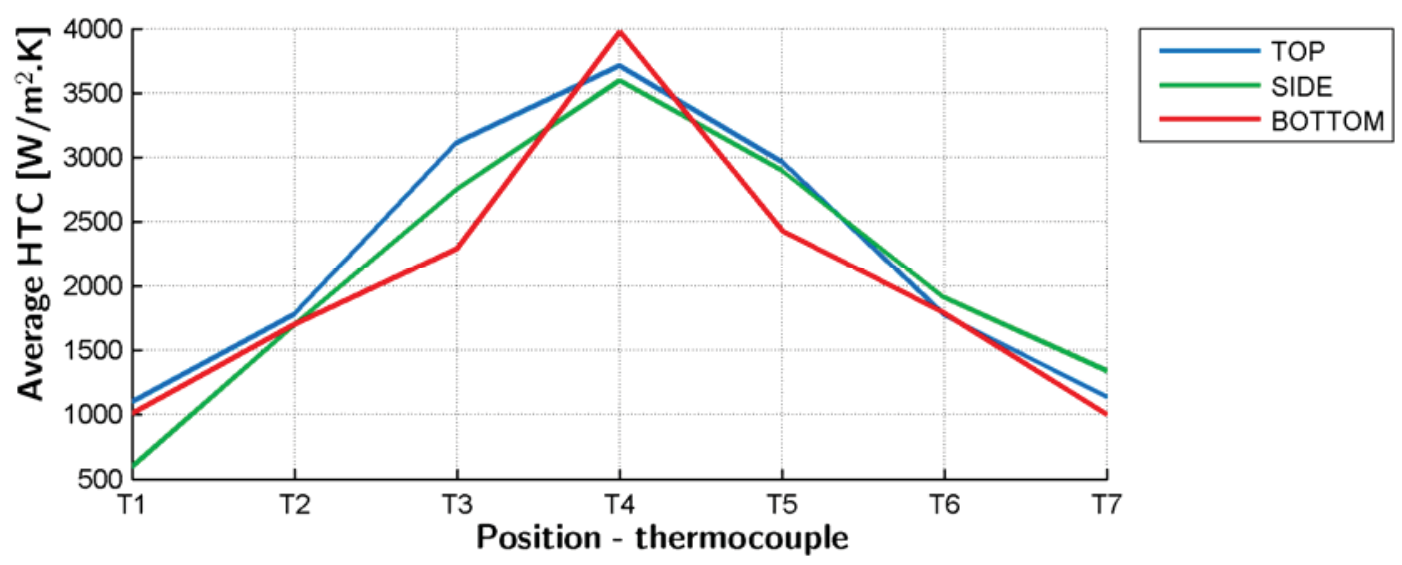

Figure 10: Average HTC in temperature interval $(650 \div 700)^{\circ} \mathrm{C}$

\section{Hydraulic nozzle - 207mm distance}

An experiment with a 0.7 bar water pressure was conducted. Under the nozzle the results are similar. In other thermocouples we can see differences. In Figure 13 the bottom orientations of the surface have a higher cooling intensity than the top 
orientation. But the trends described in the graph in Figure 12 are similar and the differences in local points in Figure 13 are probably a kind of a measurement error or the inverse calculation than a higher intensity for the bottom orientation.

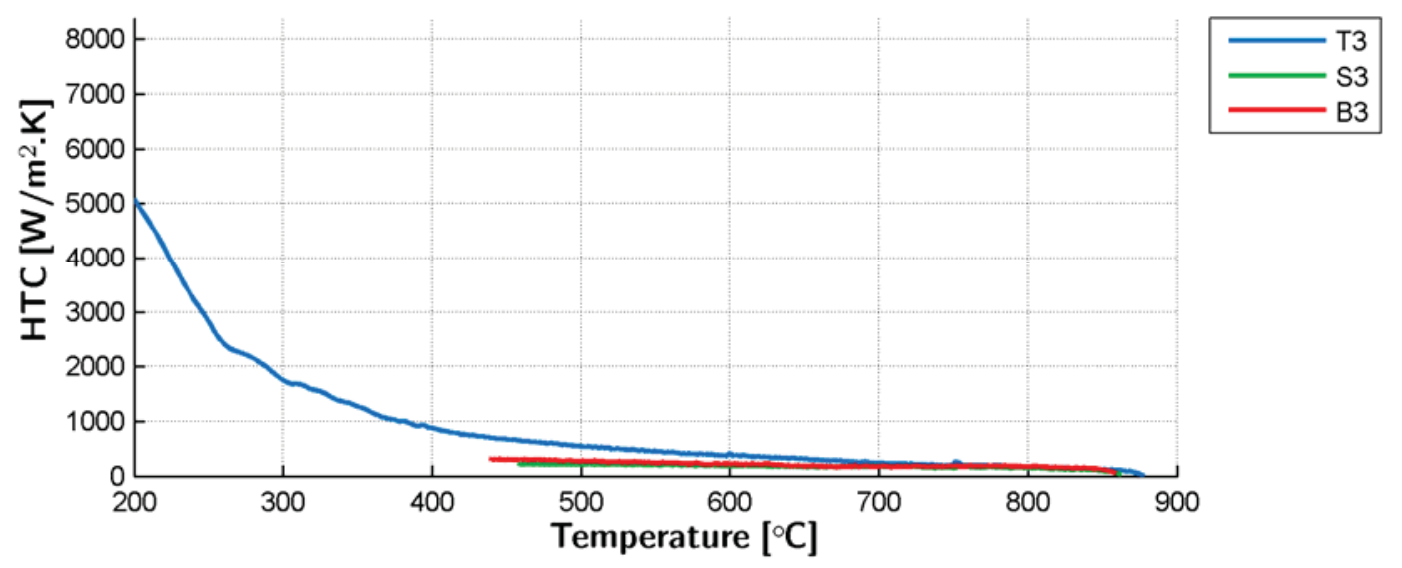

Figure 11: Thermocouples T2 - HTC vs. surface temperature for different orientation of testing plate

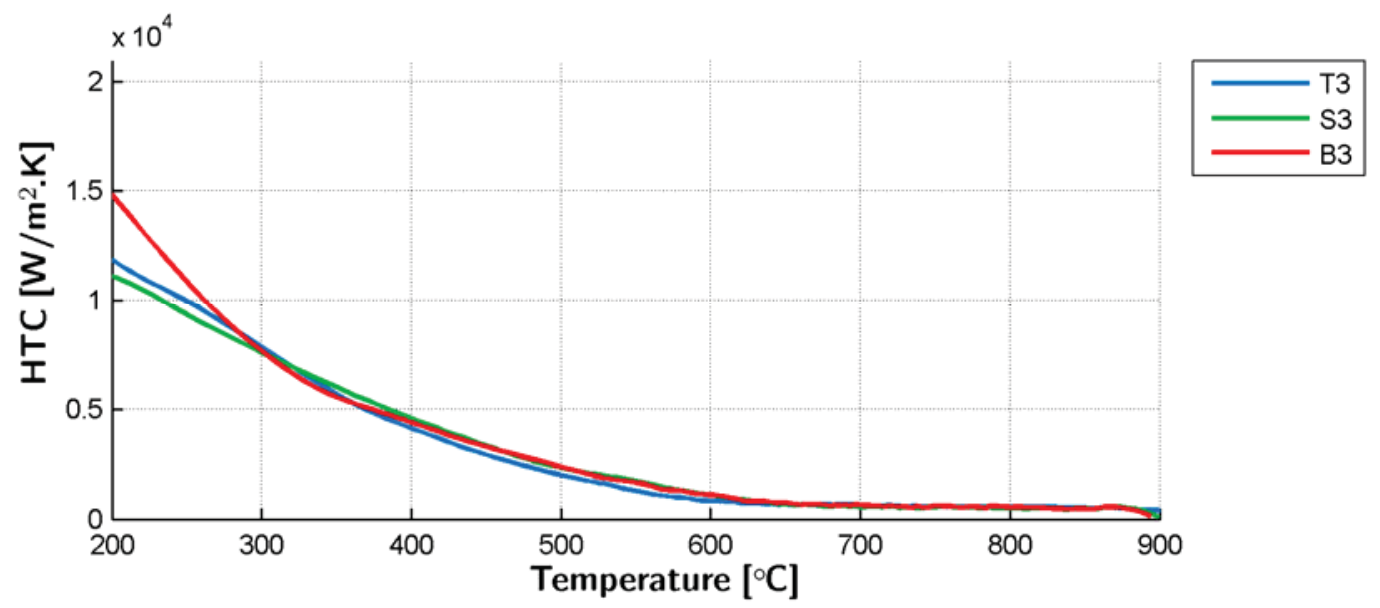

Figure 12: Thermocouples T4 - HTC vs. surface temperature for different orientation of testing plate

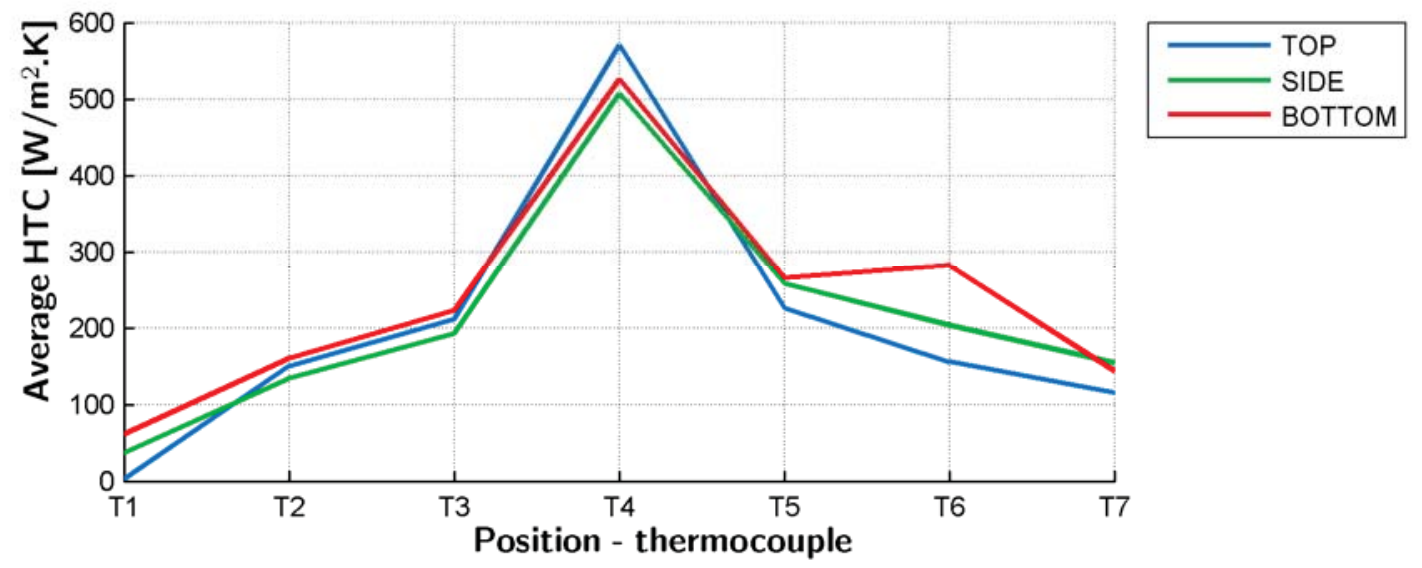

Figure 13: Average HTC in temperature interval $(800 \div 850)^{\circ} \mathrm{C}$ Hydraulic nozzle - 500 mm distance 
An experiment with a 0.7 bar water pressure and the highest distance of $500 \mathrm{~mm}$ was conducted. Results from these experiments were much influenced by the surface orientation. Even under the nozzle axis (thermocouple T4) the results are significantly different. In vertical orientation of the test plate we can see an increasing HTC near the lower roll (thermocouple T7 in Figure 16).

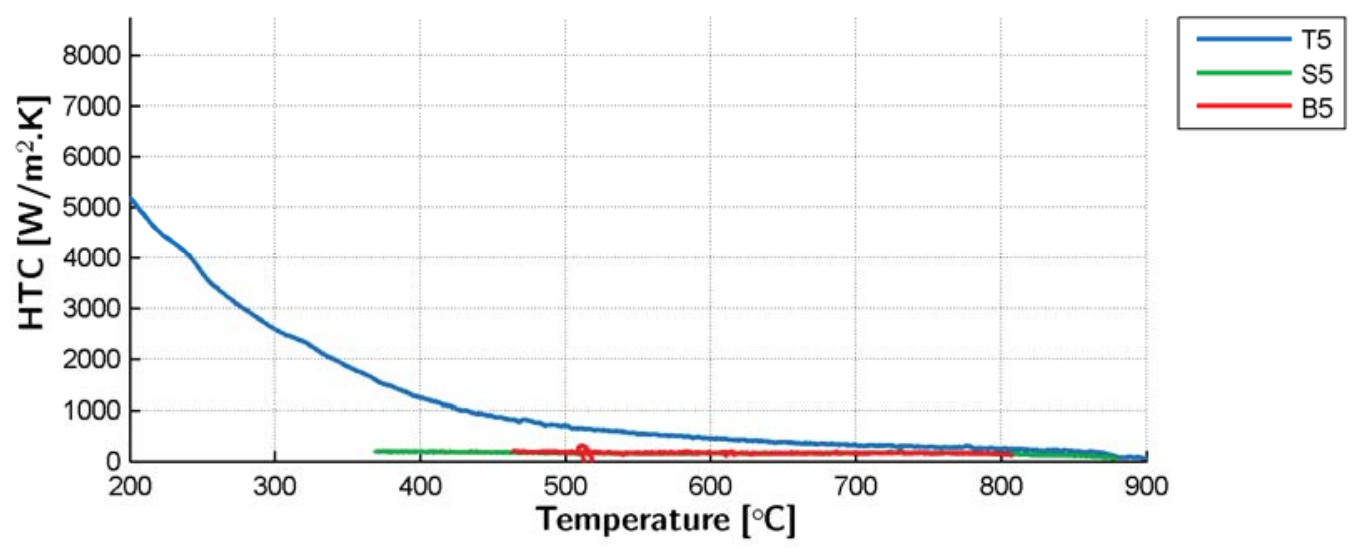

Figure 14: Thermocouples T2 - HTC vs. surface temperature for different orientation of testing plate

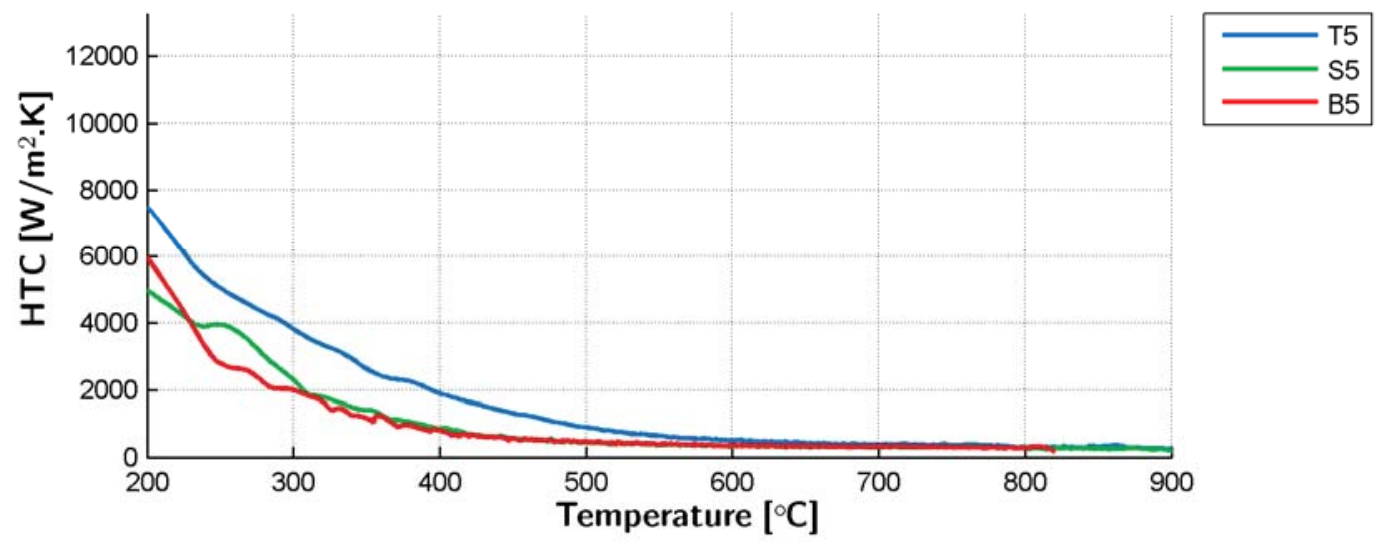

Figure 15: Thermocouples T4 - HTC vs. surface temperature for different orientation of testing plate

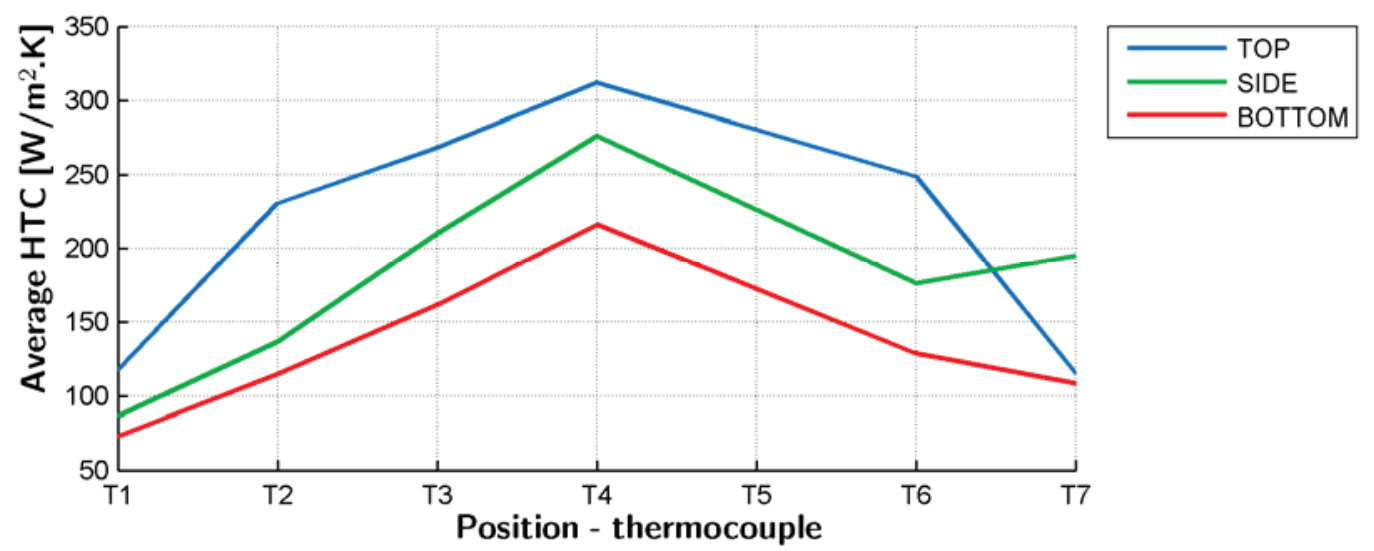

Figure 16: Average $\mathrm{HTC}$ in temperature interval $(800 \div 850)^{\circ} \mathrm{C}$ 


\section{Conclusion}

The differences among different surface orientations strongly depend on the nozzle distance and the water pressure. For high pressure the differences between top and bottom orientations can be found only in the boundary area close to the roll. In the rest of the plate the results are similar and the differences are close to the errors of the measuring. For low pressure the differences are more significant and can be found even under the nozzle axis. In vertical orientation of the test plate we can see a shift of the cooling intensity close to the bottom roll within the results. This shift can be found even for high pressures.

\section{ACKNOWLEDGEMENT}

The paper presented has been supported by the internal grant of the Brno University of Technology focused on specific research and development No. FSI-S-11-20 - Heat Transfer Intensification.

\section{RefERENCES}

[1] Horsky J., Raudensky M., Tseng A.A.: Heat Transfer Study of Secondary Cooling in Continuous Casting, AISTech 2005, Iron \& Steel technology Conference and exposition, May 9-12, 2005, Charlotte, USA.

[2] Horsky J., Raudensky M.: Measurement of Heat Transfer Characteristics of Secondary Cooling in Continuous Casting, 14th International Metallurgical \& Materials Conference, Metal 2005 May 24-26, 2005, Hradec n/Moravici, CR, ISBN 80-86840-13-1.

[3] Beck J.V., Blackwell B., Charles R. C.: Inverse Heat Conduction: Ill-posed problems, New York, Wiley, 1985, ISBN 0-471-08319-4. 